\title{
Literatura eletrónica para crianças: o caso do projeto "Murais e Literatura: A Criação Digital em Contexto Educativo"1
}

\section{Electronic Literature for Children: The case of the project "Murals and Literature: Digital Creation in an Educational Context"}

https://doi.org/10.34112/2317-0972a2019v37n75p39-66

\section{RUI TORRES ${ }^{2}$}

Ana Maria Machado ${ }^{3}$

Ana Albuquerque e Aguilar ${ }^{4}$

JÚLIA ANDRADE

Thales ESTEFANi ${ }^{6}$

\section{Luís Lucas Pereira ${ }^{7}$}

RESUMO: Este artigo tem como objetivo apresentar e descrever um projeto de literatura eletrónica para crianças em curso na Universidade de Coimbra, Portugal. Para tal, começa-se por propor um contexto de enquadramento, caracterizando a multimédia digital, baseada na integração interdisciplinar e na interação; o cibertexto e a ergodicidade textual, que assentam na abertura e na estrutura narrativa labiríntica; e o hipertexto, com suas estruturas rizomáticas, entendido como rede textual não-linear apoiada em estruturas modulares. Estes conceitos, assim considerados definidores da literatura eletrónica, são posteriormente aplicados a uma literatura digital infantil, dessa forma sustentando a abordagem subjacente à conceptualização deste projeto. $\mathrm{Na}$ descrição do projeto, abordam-se as estratégias de exploração didático-pedagógica do mesmo, propondo desse modo um modelo que possa vir a ser adotado em contextos escolares diferenciados.

PALAVRAS-CHAVE: Literatura eletrónica; literatura infantil e juvenil; ensino.

1. Os autores deste artigo utilizam o Português europeu, seguindo o Acordo Ortográfico de 1990.

2. Universidade Fernando Pessoa, Portugal.

3. Universidade de Coimbra, Portugal.

4. Universidade de Coimbra, Portugal.

5. Universidade de Coimbra, Portugal.

6. Universidade de Coimbra, Portugal.

7. Universidade de Coimbra, Portugal. 
ABSTRACT: This article aims to present and describe an electronic literature project for children in progress at the University of Coimbra, Portugal. To this end, we propose a theoretical framework, characterizing and contextualizing digital multimedia, which is based on interdisciplinary integration and interaction; cybertext and textual ergodicity, which are based on openness and the labyrinthine narrative structure; and hypertext, with its rhizomatic structures, understood as a non-linear textual network supported by modular structures. These concepts, considered as defining for electronic literature, are applied to children's digital literature, thus supporting the approach which underlies the conceptualization of this project. In the description of the project, the strategies for didactic-pedagogical exploration are approached, proposing a model that can be adopted in different school contexts.

KEYWORDS: Electronic literature; children's and youth literature; teaching.

\section{INTRODUÇÃO}

As tecnologias da informação permitiram a criação de dois tipos distintos de interação digital com o leitor: a digitalização de textos literários e as obras concebidas especificamente para o computador. $\mathrm{O}$ primeiro tipo implica a transferência de meios analógicos baseados na inscrição material do livro para uma representação digital, caracterizada por interfaces simbólicas. Esta remediação de estratégias textuais pré-existentes, transitando do papel para o pixel, constitui uma transcodificação em termos técnicos, sem transformar a textualidade linear que lhe estava inerente. Já o segundo tipo, a literatura eletrónica (que pode também ser referida como literatura digital ou ciberliteratura) obriga-nos a repensar a própria escrita e leitura, já que depende de uma construção cibernética e hipermediática que sinaliza uma apropriação das potencialidades generativas de um algoritmo, com base em procedimentos combinatórios, aleatórios ou interativos. Em diálogo com o computador, o qual é visto como máquina aberta, e não como uma simples máquina de calcular, o autor/programador joga com a máquina semiótica referida por Pedro Barbosa (1996), alterando profundamente o circuito comunicacional da literatura.

A diferença entre literatura digitalizada e literatura digital também diz respeito à literatura infantil, bem como à pedagogia que lhe está subjacente. Neste artigo, apresentamos um projeto de literatura digital infantil que se situa no âmbito da literatura eletrónica, promovendo a criatividade, a experimentação e o jogo e, dessa forma, propondo um espaço cognitivo aberto e variável que se adequa a novas 
formas de promover hábitos de leitura e escrita junto de jovens que vivem imersos numa cultura digital.

Além da possibilidade de adaptação a diferentes modalidades cognitivas, os processos de escrileitura da literatura eletrónica (BARBOSA, 2006, p. 38-39) permitem a integração interdisciplinar, configurando num único ecrã, em justaposição reflexiva, análise e interpretação textual, artes da escrita e procedimentos de programação informática, competências de navegação e co-criação de conteúdos multimédia. Partindo de tecnologias interativas em que a organização da informação pode ser não-linear, tirando partido da utilização integrada de som, imagem, texto e código, este trabalho de literatura eletrónica, realizado especificamente para crianças em ambiente escolar, poderá ser usado como ambiente de aprendizagem aberta. É isso que "Murais e Literatura", que aqui vamos apresentar, pretende alcançar.

\section{ConteXtos e enquadramento da literatura Eletrónica}

A literatura digital para crianças exige um breve enquadramento histórico da literatura eletrónica, na qual se filia, já que não se trata de uma proposta recente. Organizações como a $\mathrm{ELO}^{8}$ e a rede $\mathrm{LITeLAT}^{9}$, assim como o $\mathrm{ELMCIP}^{10}$ e inúmeras outras bases de dadosi1, mas também cursos de mestrado e doutoramento, centros de investigação, conferências, exposições e festivais internacionais parecem justificar o seu reconhecimento académico e institucional. Com uma forte tradição

8. Fundada em Chicago, Illinois, em 1999, a ELO-Electronic Literature Organization <http://eliterature.org/> organiza uma conferência internacional anual, assim como um festival e exposições. Com a Bloomsbury Press coordena uma série de livros intitulada Electronic Literature, tem três volumes publicados da Electronic Literature Collection, dinamiza o repositório de informação Electronic Literature Directory, e publica livros e relatórios.

9. Fundada em 2015 em Buenos Aires, Argentina, a LITeLAT-Red de Literatura Electrónica Latinoamericana $<$ https://litelat.net> congrega académicos, investigadores e artistas que se interessam por temas/obras de literatura electrónica no contexto latinoamericano.

10. Resultado de um projecto de 3 anos (2010-2013) coordenado pela Universidade de Bergen, Noruega, e financiado pelo Humanities in the European Research Area (HERA) JRP for Creativity and Innovation, o ELMCIP-Electronic Literature as a Model of Creativity and Innovation in Practice <https://elmcip.net> mantém uma Knowledge Base com 13172 registros (dados de Janeiro 2019), artigos e livros, e uma Anthology of European Electronic Literature.

11. Algumas das mais importantes bases de dados estão agregadas no CELL-Consortium on Electronic Literature $<$ http://cellproject.net/>, nomeadamente: CIBERIA (Espanha), NT2 (Canadá), Po-ex.net (Portugal), ELMCIP (Noruega), ADEL (Alemanha), I Love E-poetry (EUA), Brown Digital Repository (EUA), ADELTA (Austrália), Electronic Book Review (EUA), Hermeneia (Catalunha, Espanha), e Electronic Literature Lab (EUA). 
em Itália, França, Espanha, Alemanha e Portugal, a qual remonta aos anos 1960 e 1970 (FUNKHOUSER, 2007; BARBOSA, 1996), assumindo posteriormente, nos anos 1980, um papel importante nos Estados Unidos da América (GLAZIER, 2002; RETTBERG, 2019), a que se adiciona a internacionalização recente com a WWW, a literatura eletrónica refere-se a formas verbais, sonoras e visuais que têm a sua origem no computador (são objetos nativos digitais) e que apenas podem ser lidas em computadores ou outros dispositivos digitais. Embora uma categorização por género possa parecer restritiva, já que novos sub-géneros vão aparecendo em resposta a novos programas, a recente divisão proposta por Rettberg parece-nos acertada e suficientemente inclusiva: "Combinatory Poetics," "Hypertext Fiction," "Interactive Fiction and Other Gamelike Forms," "Kinetic and Interactive Poetry," "Network Writing" (2019).

Se, por um lado, uma estrutura não-sequencial de informação, como aquela que hipertexto e hipermédia possibilitam, contribui para o exercício da criação literária, por outro lado ela obriga a uma redefinição do próprio conceito de pedagogia do texto literário. A transformação que se opera na passagem do físico ao virtual constitui uma oportunidade de repensar os próprios conceitos de texto. Para Katherine N. Hayles, a textualidade eletrónica "presents us with an unparalleled opportunity to re-formulate fundamental ideas about texts and, in the process, to see print as well as electronic texts with fresh eyes" (HAYLES, 2003, p. 263) e, para Marie-Laure Ryan, o desenvolvimento dessas mesmas textualidades "led to a rediscovery and critical investigation of print and the Codex book” (RYAN, 1999, p. 10).

\subsection{Características da multimédia digital}

Uma estratégia para pensar o livro infantil em meio digital deve ter em consideração as propriedades do novo meio. Packer e Jordan (2002) apontam cinco características essenciais da multimédia digital, as quais remetem para um conjunto de antecedentes estéticos e técnicos: integração, interatividade, imersão, hipermédia e narratividade (PACKER; JORDAN, 2002, p. xxxv). Seguindo as definições propostas pelos autores, interessa aqui reter os dois primeiros conceitos. Entende-se por integração a combinação de formas artísticas e tecnologia numa forma de expressão híbrida, isto é, a convergência de múltiplos meios em plataformas de agregação. $O$ computador é assim visto como uma máquina universal, anulando as diferenças materiais entre os meios e esta integração permite a interação e a colaboração em rede. 
Packer e Jordan definem interatividade como a capacidade dada ao utilizador para manipular e afetar a sua experiência mediática diretamente. Ao inverter o paradigma da massificação por um novo, de participação, personalização e individualização, a multimédia digital confere liberdade, mas também responsabilidade, ao leitor. Para Packer e Jordan, as estratégias formais e estéticas que derivam dos conceitos acima enunciados denomina-se narratividade, entendida como não-linearidade e abertura (PACKER; JORDAN, 2002, p. xxxv).

Um dos aspectos mais críticos da interatividade é que o meio digital permite a alteração, mistura e justaposição de elementos, isto é, ele promove a recriação e a remistura, tendo por isso uma aptidão para a transformação, em vez da conservação que tipificava o livro analógico. Esta transferência de responsabilidade do autor para o leitor, do professor para o aluno, obriga-nos a pensar em termos de variabilidade, aspecto que Lev Manovich considera essencial na linguagem dos novos média, que não se apresentam como algo fixo e permanente, mas antes podendo existir em versões diferentes e potencialmente infinitas (MANOVICH, 2001, p. 36).

\subsection{Cibertexto e ergodicidade textual}

A condição instável dos novos média torna relevante a discussão da desmaterialização do próprio conceito de texto na literatura electrónica. Pedro Barbosa (2006) propôs nesse sentido uma homologia entre o modelo quântico da física e a teoria do cibertexto, de forma a dar conta dos textos múltiplos e generativos. Segundo Barbosa, existe uma dialéctica entre a virtualidade e a actualidade que o texto generativo realiza, a qual dá também conta das modalidades de representação simbólica com que construímos a nossa percepção do mundo (BARBOSA, 2006, p. 11).

Também Espen Aarseth define o cibertexto como aberto, organizando-se como um mecanismo que permite ao leitor configurar caminhos. Esta abertura não existe apenas a um nível cerebral, mas num "sentido extranoemático" (AARSETH, 2005, p. 19), uma abertura programada no próprio dispositivo textual, posicionando a comunicação literária eletrónica e a textualidade digital ao nível da automação. $\mathrm{O}$ termo proposto por Aarseth é o de texto "ergódico", que tem origem etimológica em ergon (do grego: trabalho, obra) e hodos (do grego: percurso, via). Assim interpretado, o cibertexto: 
Literatura eletrónica para crianças: o caso do projeto "Murais e Literatura...

não é uma forma de texto «nova», «revolucionária», com capacidades que só se tornaram possíveis por meio da invenção do computador digital. Nem constitui uma quebra radical com a textualidade à moda antiga, embora fosse fácil fazer parecer que sim. O cibertexto é uma perspectiva acerca de todas as formas de textualidade, um modo de expandir o âmbito dos estudos literários de forma a incluírem fenómenos que hoje em dia se consideram exteriores ou marginalizados pelo campo da literatura. (AARSETH, 2005, p. 36-37)

Os textos ergódicos "produzem estruturas verbais, com efeito estético" (AARSETH, 2005, p. 21); eles são, como o autor afirma, "máquinas de produzir variedade de expressão" (p. 21), situando-se portanto num espaço reconfigurado pela rede, o qual deixou de significar uma entidade fixa.

\subsection{Hipertexto e estruturas Rizomáticas}

Convém a este propósito lembrar que para Deleuze e Guattari (1980), o rizoma, que por definição é não-linear, indeterminado e sem um centro, apresenta seis princípios. Pierre Lévy associou-os a um conjunto de princípios abstractos do hipertexto (LÉVY, 2004, p. 25-26). O princípio da metamorfose diz respeito ao estado de abertura e processo a que já nos referimos. Por ser um espaço onde convergem múltiplas interações, ele está sujeito a uma permanente re-negociação. As inscrições na rede são, por outro lado, heterogéneas, já que o hipertexto é composto por elementos (meios) de espécie diferente. A rede é uma estrutura modular, ou fractal (MANOVICH, 2001, p. 30), apresentando-se numa multiplicidade que Deleuze e Guattari e, depois deles, Lévy, caracterizam como encaixe das escalas. Uma vez que os nós da rede podem ser compostos por outras redes de nós e conexões, tratar-se-ia igualmente de um meta-meio, um meio que permite criar novos meios e novas linguagens. A inexistência de uma ordem interna que regule o rizoma (e a rede) ou a sua expansão leva os autores a propor o princípio de exterioridade. Na perspetiva de Lévy, o crescimento da rede está dependente da colaboração (ou inteligência) coletiva, indeterminada e desregulada por essência. O princípio da topologia refere-se ao facto de não ser possível descrever com precisão um lugar a que o ciberespaço e a rede estão associados. Não há um mapa, mas apenas fluxos, espaços sem centro, funcionando numa lógica de proximidade e vizinhança, de caminhos e atalhos. Por fim, Lévy aplica o conceito de mobilidade dos centros usado por Deleuze e Guattari 
para descrever o rizoma, explicando que não existe um único centro na rede hipertextual, mas antes um conjunto diversificado de centros em perpétua volubilidade.

\section{Literatura digital infantil: PRINCÍPIOS PARA UMA Literacia EM REDE}

Face ao exposto, também urge repensar aquele que seria um novo livro adequado às necessidades da cultura tecnológica do nosso tempo. Como Magalhães e Alçada reconhecem, a literatura infantil é um "espelho do mundo", refletindo "(...) com clareza e nitidez a época a que pertence” (1990, p. 7). Assim, a possibilidade de transcodificar o livro infantil num documento híbrido e multimodal, no qual texto, som e imagem possam integrar-se com interatividade, narratividade, ergodicidade e hipertextualidade, é uma atividade necessária.

No seu relatório sobre culturas participativas, Jenkins et al. (2006) mostram que os jovens criam e partilham conteúdos digitais na Internet a um ritmo acelerado, e isso obriga a uma alteração das estruturas de ensino, que devem ser adaptadas às literacias dos novos média. De acordo com estes investigadores, devemos considerar um conjunto de novas competências que justificam a estratégia pedagógica com que abordamos o projeto em discussão. As competências estudadas pelos autores, que passamos a citar, são as seguintes:

Jogo - os jovens experimentam o ambiente que os rodeia como uma forma de resolver problemas;

Performance - os jovens adotam identidades alternativas com o objetivo de improvisar e descobrir;

Simulação - os jovens interpretam e constroem modelos dinâmicos acerca dos processos existentes no mundo real;

Apropriação — os jovens remisturam e combinam conteúdos mediáticos para criarem novos sentidos;

Multitarefas - os jovens saltam entre contextos e suportes mediáticos distintos;

Cognição distribuída - os jovens interagem com ferramentas que expandem as capacidades mentais;

Inteligência Coletiva - os jovens comparam o conhecimento de forma a atingir objetivos comuns e coletivos (de grupo);

Julgamento - os jovens avaliam a credibilidade de fontes de informação diferentes; 
Literatura eletrónica para crianças: o caso do projeto "Murais e Literatura...

Navegação transmediática - os jovens percorrem o fluxo hipertextual das narrativas e da informação, cruzando modalidades múltiplas;

Networking - os jovens procuram informação, sintetizam e disseminam informação;

Negociação - os jovens viajam entre comunidades diversas, compreendendo diferenças e respeitando múltiplas perspectivas (JENKINS et al., 2006, p. 4, tradução nossa).

A formulação de estratégias para uma literacia digital implica considerar-se a capacidade de ler e escrever, mas também a de interagir, por via da escrileitura multimediática, com um conjunto diversificado de plataformas, ferramentas e média. Neste contexto, deve ser função do professor fomentar, por um lado, e acompanhar e analisar criticamente, por outro, estas novas modalidades de conhecimento, interpretando-as adequadamente e enquadrando-as no contexto académico, científico e pedagógico apropriado.

Jay David Bolter, que tem estudado a remediação do livro no hipertexto, referese ao livro infantil como algo natural para ser remediado em meio digital, uma vez que as crianças sempre leram de um modo hipertextual: "[c] hildren have known for decades (since the flourishing of children's literature in the nineteenth century) how to read hypertextually" (BOLTER; GROMALA, 2003, p. 81). Aliás, toda uma tradição de livros "interativos" criados em papel está em sintonia com a noção de cibertexto proposto por Aarseth. No caso de Bolter e Gromala, os autores referem-se a livros pop-up ou com formas não convencionais, entre múltiplas outras estratégias. Os autores argumentam por isso que "children treat the book as a reflective interface." (BOLTER; GROMALA, 2003, p. 82).

Esta interface reflexiva também se estende à multimodalidade. Nos seus estudos sobre literatura infantil, Peter Hunt explica que o livro infantil mistura diversas formas artísticas: "it involves and integrates words and pictures, it overlaps into other modes - video, oral storytelling - and other art forms" (HUNT, 1994, p. 1).

Uma literatura digital infantil deve por isso participar das modalidades expressivas do novo meio que foram descritas em cima, aproximando-se de um conceito de jogabilidade. Aliás, como refere Hayles, "[t] he demarcation between electronic literature and computer games is far from clear; many games have narrative components, while many works of electronic literature have game elements" (HAYLES, 2007, n.p.). Também para Markku Eskelinen, "player structure, reminds us (...) certain fundamental differences between literature and games" (2004), podendo 
concluir-se que o computador se apresenta como uma máquina de conhecimento (máquina semiótica) que integra e dissolve as fronteiras entre jogo e literatura.

\subsection{A literacia Digital infantil em SAla De AUla}

Jogabilidade e ludicidade são aspectos com que a literatura eletrónica, por ser caracterizada pela integração e interatividade, poderá contribuir para uma redefinição da literatura infantil. Krystina Madej, nas suas propostas para a criação de narrativas digitais infantis, explica que os ambientes digitais permitem a convergência de educação e entretenimento (2003), o que alguns autores apelidam de entretenimento educacional, ou edutainment: "[the] design of edutainment includes the design of both entertainment and educational aspects in a design artifact" (JEGERS; WIBERG, 2005, p. 124).

Estes artefactos textuais jogáveis, que estão em sintonia com os dispositivos de leitura que os jovens usam no seu quotidiano, implicam, como Peters e Lankshear observaram, um tipo de literacia crítica, a qual oferece novas "possibilities for enlarging and enhancing conceptions and practices of critical literacy through the reflective appropriation of electronic technologies," (PETERS; LANKSHEAR, 1996, p. 52), e que tem como objetivo educativo "[d] esarrollar la conciencia crítica" (CASSANY, 2006, p. 82), também por meio do desenvolvimento das habilidades face ao digital.

Tendo em consideração estas questões relacionadas com a pedagogia do texto literário, Marcel Cornis-Pope e Ann Woodlief propuseram um "re-creative pedagogical model of literary interpretation based on strategies of rereading/rewriting as part of a community of readers" (CORNIS-POPE; WOODLIEF, 2002, p. 147). Uma tal pedagogia crítica e interativa, que traz para a sala de aula práticas de leitura e de escrita em linha, propiciando aprendizagens que, muitas vezes, ainda não são reconhecidas pelo currículo oficial (CASSANY, 2011), mas que consubstanciam a aprendizagem invisível (COBO; MORAVEC, 2011), permitirá aos estudantes terem uma "ample opportunity to move from reading to writing, and from understanding to reformulation, so as to experience a stronger mode of cultural construction." (CORNIS-POPE; WOODLIEF, 2002, p. 160). Uma vez encorajados a comprometerem-se com os processos multi-sequenciais da crítica hipertextual, os alunos podem se beneficiar das vantagens gerais da hipertextualidade: "multilinear or networked organization, open-endedness, greater inclusion of non-textual information, interactive authorship" (CORNIS-POPE; WOODLIEF, 2002, p. 160). 
A textualidade digital exige o envolvimento de professores e alunos em atividades interdisciplinares. De forma a compreender plenamente o potencial dos textos digitais e a desenvolver a literacia digital dos estudantes (UNESCO, 2018), precisamos criar novas condições de aprendizagem - e professores e alunos, autores e leitores, precisam se envolver em novas modalidades cognitivas. Trabalhos colaborativos como aquele que descrevemos a seguir podem fomentar a integração da crítica no processo criativo, já que os jovens estudantes são capazes de estabelecer ligações intertextuais perspicazes, fazendo parte do processo de autoria, sendo-lhes concedida a liberdade de interagir com a própria escrita e a sua codificação. Este processo é reflexivo porque ao usar e ao manipular os novos média, os jovens descobrem as próprias relações entre crítica e jogo, teoria e criatividade. Dessa forma, os poemas e as narrativas interativas e multimodais que fazem parte da estratégia do projeto "Murais e Literatura" podem contribuir para uma conceção criativa do próprio ato de ler em meio digital.

\subsection{A literatura infantil e JUVEnil Eletrónica}

A discussão da autonomia genológica da literatura infantil e juvenil, por parte de autores como Peter Hunt (1990) e Juan Cervera (1992), entre outros, ou a sua consideração como um sistema estratificado de subsistemas dinâmicos de natureza estética e social, como explica Zohar Shavit (2003) enquadrada pela dinâmica da teoria dos polissistemas de Even Zohar (1990), repetem-se, num contexto de esferas culturais mais alargadas, a propósito da literatura infantil e juvenil eletrónica, vista a sua relação com videojogos, livros ilustrados e software educativo (RAMADA PRIETO, 2017).

De facto, boa parte dos elementos constituintes da literatura infantil e juvenil mantêm a sua relevância na literatura infantil e juvenil eletrónica: recurso à voz ativa, ao discurso direto e a frases mais curtas, sem prejuízo de obras com vocabulário ou sintaxe mais elaborados (ZILBERMAN, 2003); a linguagem carregada de significados até o máximo grau possível (GÓES, 2010); o rigor estético comum ao da literatura para o público adulto; a especificidade do destinatário preferencial (RAMOS, 2003; RODRIGUES, 2007), uma vez que os livros são idealmente pensados em função da faixa etária a que se destinam, podendo mesmo supor sugestões de níveis de leitura diferentes - leitores iniciantes, leitores autónomos e leitores com mais experiência (CUNHA, 1999); o crivo de mediadores (pais, professores, bibliotecários); e, finalmente, a relação multimodal com as imagens, um fator que 
singulariza a produção de livros para crianças, assumindo a ilustração um papel de enorme relevância na fruição da obra e no desenvolvimento da cognição de leitores iniciantes (JIMENEZ, 1995). A opção de valorização do receptor em sentido lato, defendida por Hunt (2010), parece responder melhor à efetiva relação texto-leitor. Ao considerar como literatura infantil os "livros lidos por; especialmente adequados para; ou especialmente satisfatórios para membros do grupo hoje definido como crianças" (HUNT, 2010, p. 96), o autor expande a noção do género e abarca diferentes públicos, estilos e suportes, criando uma abertura para possibilidades de criação e de fruição próximas das características da literatura digital.

Dentro do campo da literatura eletrónica, o subcampo da literatura infantil e juvenil digital se encontra em crescimento. O mercado (sobretudo o anglófono) disso dá sinais, com cada vez mais aplicações destinadas a diferentes dispositivos, bem como com desenvolvimento de obras, maioritariamente narrativas, de realidade aumentada e de realidade virtual. Do mesmo modo, também a crítica e a investigação académica têm progressivamente virado as atenções para esta área, o que contribui não apenas para a visibilidade da literatura infantil e juvenil digital, como também para a sua legitimação. As exposições "Kid E-Lit" (Bergen, 2015) e "E-Lit for Kids" (Porto, 2017), ambas associadas à conferência da Electronic Literature Organization, o Bologna Ragazzi Digital Award, atribuído desde 2012, no âmbito da Feira do Livro Infantil de Bolonha, ou o próprio prémio Jabuti, com a categoria Infantil Digital (de 2015 a 2017), têm oferecido um importante contributo ao nível da curadoria destas obras.

Para a delimitação e autonomização da literatura infantil e juvenil digital, muito tem contribuído o grupo de investigação GRETEL, da Universidade Autónoma de Barcelona, sobretudo no que respeita à classificação das narrativas digitais (TURRIÓN, 2014) e à sistematização das características que permitem agrupá-las e, consequentemente, didatizá-las (GRETEL, 2014; MANRESA; REAL, 2015; RAMADA PRIETO, 2017).

Em Portugal, embora não haja ainda referências explícitas à literatura infantil e juvenil digital nos documentos orientadores das práticas letivas, quer o Perfil dos Alunos à Saída da Escolaridade Obrigatória (ME, 2017), quer as Aprendizagens Essenciais: Português (ME, 2018) para os diferentes níveis dos ensinos básico e secundário abrem espaço à leitura de texto multimodal, numa "pluralidade de géneros textuais, em contextos que o digital tem vindo a ampliar", com vista a "uma literacia mais compreensiva e inclusiva" (ME, 2018). Neste sentido, o Plano 
Nacional de Leitura 2027 apoia, desde 2018, a leitura de Alice Inanimada, tradução portuguesa de Inanimate Alice.

Como sublinham Ramada Prieto e Teresa Colomer (2010), entre outros, a emergência da literatura infantil e juvenil e o seu reconhecimento académico, conjugados com o ambiente eletrónico e com a deriva literária pós-moderna, incentivam o surgimento da literatura infantil e juvenil eletrónica, herdeira de alguns dos traços que Landow identificou entre o espaço eletrónico e a literatura pós-moderna, nomeadamente a maior liberdade do leitor, a navegação desordenada, a ludicidade, as descontinuidades etc. (1997, p. 17).

Este deslizamento é particularmente evidente no livro ilustrado digital infantil pela exploração e expansão da multimodalidade do livro ilustrado impresso, pelo que esse tipo de livro será a primeira modalidade a apresentar neste novo projeto.

\section{3. "Murais e Literatura”: um projeto de literatura digital INFANTIL}

Em Portugal, a literatura eletrónica infantil e juvenil é ainda uma miragem. No campo da literatura, a chamada "Biblioteca de livros digitais"12, do Plano Nacional de Leitura, inclui apenas livros com escassa animação e versão audiolivro, suscitando alguma indefinição ontológica entre textos digitais e digitalizado ${ }^{13}$. Apenas as obras de caráter didático ensaiam alguma interatividade, com hiperligações para esclarecimentos lexicais, e multimedialidade com ligação para vídeos informativos.

Registre-se, também, que a já referida exposição “E-Lit for Kids” (Porto, 2017), com curadoria de Mark Marino, Astrid Ensslin, María Goicoechea e Lucas Ramada Prieto, não continha nenhuma obra portuguesa.

12. http://www.planonacionaldeleitura.gov.pt/biblioteca/index.php

13. Decorrente das ações de formação destinadas a professores e educadores, asseguradas por Ana Maria Machado e Ana Albuquerque e Aguilar, do Centro de Literatura Portuguesa da Universidade de Coimbra, no âmbito do projeto de investigação "Inanimate Alice: Tradução de Literatura Eletrónica em Contexto Educativo", em colaboração com o Plano Nacional de Leitura (PNL 2027) e com a Direção-Geral de Educação portugueses (vf. http://pnl2027.gov.pt/np4/formacao_literatura_eletronica.html), verificou-se no final de fevereiro de 2019 a inclusão de ligações para obras digitais no portal do PNL, passando a incluir, entre outros, a tradução de Inanimate Alice, obras digitais de Rui Torres e do coletivo Wreading Digits, e dois Arquivos digitais: o Arquivo Digital da Literatura Experimental Portuguesa <https://po-ex.net/ > e o Arquivo digital colaborativo do Livro do Desassossego de Fernando Pessoa <https://ldod.uc.pt/>. (vf. http://pnl2027.gov.pt/np4/livrosdigitais.html). 
O projeto "Alice Inanimada: Tradução de literatura eletrónica em contexto educativo"14, alocado no Centro de Literatura Portuguesa (Universidade de Coimbra), foi criado justamente para fazer face a este vazio. Tendo como público-alvo estudantes entre 10 e 18 anos, a obra foi apropriada pelo ensino (PULLINGER, 2015) de inglês língua materna ou língua estrangeira, sendo usada em vários países, incluindo a Austrália, onde o título foi introduzido no currículo.

A obra Inanimate Alice já tinha sido traduzida em seis línguas (espanhol, francês, alemão, italiano, japonês e indonésio). Ora, sendo o português a quarta língua mais falada do mundo (com 260 milhões de falantes em quatro continentes), a existência de uma versão portuguesa justificava-se plenamente, tendo sido esse o primeiro escopo da equipa (MACHADO et al., 2018). Numa segunda fase, traduziram-se os guiões pedagógicos e preparam-se novos materiais adaptados ao sistema de ensino português. Todo este trabalho teve como objetivo introduzir a leitura de Alice Inanimada nas escolas básicas e secundárias, tornando-se os seus dois primeiros episódios ${ }^{15}$ os primeiros textos a serem lidos nas escolas portuguesas. ${ }^{16}$

Enquanto se aguardam decisões ministeriais mais claras no que concerne à adoção da literatura digital e à possibilidade de um financiamento que permita disponibilizar os episódios aos alunos, a experiência pedagógica com Alice Inanimada impulsionou uma parte da equipa a lançar-se num outro projeto, aproveitando o know-how adquirido ao longo da tradução de Alice Inanimada e da preparação dos guiões pedagógicos.

Continuando a ter o ensino como preocupação maior, o projeto "Murais e Literatura: A Criação Digital em Contexto Educativo" ${ }^{17}$ visa criar um conjunto de obras literárias digitais a que se seguirá a sua exploração didático-pedagógica, sempre subjacente ao ato criativo. Mantendo a coordenação de Ana Maria Machado e a participação de Ana Aguilar, a equipa abriu-se a três outros doutorandos do programa em Materialidades da Literatura e do Departamento de Engenharia Informática da Universidade de Coimbra, respetivamente, Júlia

14. A equipa é coordenada por Ana Maria Machado e envolve dois alunos pós-graduados, Ana Albuquerque e Aguilar e António Oliveira, o produtor executivo de Inanimate Alice, Ian Harper, e, mais recentemente uma estudante brasileira de pós-doutoramento, Alice Matsuda. <http://www.uc.pt/fluc/clp/inv/proj/meddig/iatld>

15. Produzidos com tradução portuguesa, e gentilmente facultados por Ian Harper e Chris Joseph, mas ainda não disponíveis online.

16. Uma descrição detalhada da experiência foi apresentada por Ana Maria Machado, Ana Albuquerque e Aguilar e Alice Atsuko Matsuda na Electronic Literature Conference (Montréal, 2018): "Is there a gap in the classroom? Inanimate Alice in Portuguese schools".

17. https://www.uc.pt/fluc/clp/inv/proj/meddig/murlit/ 
Andrade, Thales Estefani e Luís Lucas Pereira, e à consultoria técnica do poeta e investigador Rui Torres.

Enquadrado no âmbito do trabalho criativo infantil em ambiente digital, o projeto colaborativo em desenvolvimento inspira-se na experiência artístico-literária que resultou no livro impresso História do Capuchinho Vermelho Contada a Crianças e Nem por Isso, escrito por Manuel António Pina, a partir de pinturas de Paula Rego.

Assim, no projeto "Murais e Literatura", a relação entre texto verbal e composição visual assume também características inversas às que são comummente encontradas na literatura infantil e juvenil impressa. De facto, em geral, no livro ilustrado, a elaboração das imagens é antecedida por uma construção textual que serve de guia a essa produção - o mesmo ocorrendo com o roteiro que um livro ilustrado apresenta. Ao ilustrador é exigido que mergulhe de forma crítica e analítica no texto ou roteiro do livro, a fim de alcançar várias leituras possíveis e, posteriormente, investir na produção de imagens que representem as expressões espaciais e temporais dos contextos ficcionais pretendidos e, ainda mais importante, expresse os sentidos sensoriais e significativos da história, de forma a produzir imagens provocadoras de poesia (FITTIPALDI, 2008, p. 104). Pelo contrário, na proposta de transposição apresentada, as imagens antecedem o texto, obrigando a um percurso analítico e criativo inverso ao processo mais comum.

Transitando do impresso para o digital, pretende-se agora criar uma obra digital infantil, em língua portuguesa, inspirada em murais (1958) do pintor Costa Pinheiro (1932-2015), encomendados para três salas do jardim infantil do Instituto Maternal Bissaya Barreto, em Coimbra.

A solicitação da pintura destes murais para um espaço público infantil por parte do professor Bissaya Barreto $^{18}$ responde a um programa estético com uma peculiar sensibilidade para a beleza dos espaços públicos infantis, inerente ao seu projeto educativo e, conforme defendia, condição sine qua non do desenvolvimento da criança: "O amor à beleza, assim criado, passa a fazer parte integrante do seu modo de ser, com ele se familiariza e a educação integra-o nos fundamentos da sua personalidade" (BARRETO, 1970, p. 164-165).

Por seu lado, na feição surrealizante e figurativa que António Costa Pinheiro imprime à obra, percebe-se um traço deliberadamente infantil, comum aos artistas

18. Professor catedrático da Faculdade de Medicina da Universidade de Coimbra e Presidente da Junta Distrital de Coimbra. 
da segunda metade dos anos 50, já em superação da arte abstrata, mas com um forte compromisso com a imaginação (DIAS, 2008).

A possibilidade de também o digital imprimir uma forte impressão estética nas crianças do século XXI esteve na origem da migração e da remediação dos murais de Costa Pinheiro e na consequente criação de uma obra de literatura eletrónica infantil.

\subsection{Descrição do projeto}

Entre outros sentidos que a designação "Murais e Literatura" possa sugerir, quis-se evidenciar a dimensão interartística e colaborativa do trabalho que, como se disse, parte de três pinturas murais de Costa Pinheiro e as faz migrar para o ambiente digital, onde a narrativa pictórica vai ser remediada, na medida em que o meio digital se apropria dos processos de significação dos murais ao nível técnico, formal e temático, procurando enriquecer o seu potencial representativo (BOLTER; GRUSIN, 1999).

Os artefactos estéticos a criar serão textos simultaneamente imigrantes e nativos, para usar a adaptação da terminologia de PRENSKY (2001) proposta por SCHWEBS (2014) e STICHNOTE (2014). Esta natureza dupla justifica-se porque, no processo de transcodificação, se procura manter a identidade visual dos murais, quer pelo recurso às imagens ou a fragmentos, quer pela sua expansão gráfica. A manipulação das imagens está condicionada pela história a contar e pela aliança entre realidade e fantasia que quer imprimir em cada uma das três obras literárias.

Assim, pensando no potencial da literatura eletrónica para a formação ficcional e leitora do aluno, em função da natureza diferente e multidisciplinar que a relaciona com formas de cultura diversas, a partir de um input comum, projetaram-se três histórias independentes e adequadas a distintas faixas etárias. A primeira, para crianças de 4 anos, tem características formais que a assemelha a uma correspondente digital do livro ilustrado; a segunda explora as possibilidades da geração textual a partir do corpus da literatura tradicional oral infantil e destina-se a crianças com mais de 6 anos; a terceira consiste num conto não-linear destinado a crianças de 9 e 10 anos. Estes destinatários preferenciais são extensíveis, uma vez que cada uma destas obras oferece diferentes possibilidades de leitura em função da hipertextualidade e também do nível de dificuldade. A par da fruição estética, pretende-se que a criança crie referências literárias, desenvolva a sua literacia digital, o nível de ludicidade e a capacidade de apreciar algumas disrupções narrativas, quer ao nível formal e tecnológico, quer ao nível do conteúdo, como sejam as roturas com os 
esquemas das histórias tradicionais, pelo que as diferentes versões estão preparadas para diferentes faixas etárias.

Simultaneamente, tira-se partido do processamento visual de ilustrações estáticas e animadas em narrativas multimodais. Num estudo empírico incidindo sobre crianças de 4 a 6 anos de idade, as pesquisadoras Adriana G. Bus e Zsofia K. Takacs encontraram resultados bastante positivos de que o movimento (pequenas animações) incluído em ilustrações pode guiar também a atenção visual das crianças, auxiliando a encontrar um detalhe importante na ilustração, o que resulta em fixações mais longas em partes importantes, de modo a combinar imagem e texto verbal narrado de forma mais eficaz que em experiências com ilustrações estáticas (TAKACS; BUS, 2016). Como ponto de partida para a pesquisa, Takacs e Bus basearam-se na teoria da codificação dupla, segundo a qual duas fontes de informação ou estímulo que não são incompatíveis podem ser processadas simultaneamente sem causar sobrecarga cognitiva, "em canais separados, mas interconectados, aumentando assim representações mentais e traços de memória que conectam detalhes de imagens com frases na narrativa" (PAIVIO, 2007 apud TAKACS; BUS, 2016, p. 2, tradução nossa). Segundo Takacs e Bus, contudo, o processo de codificação dupla só acontece com animações que estão intimamente ligadas ao conteúdo do texto verbal da história. Para aquelas que possuem apenas função decorativa, a hipótese apresentada pelas pesquisadoras é a de que podem distrair as crianças, "colocando uma alta carga cognitiva em sua memória de trabalho" (TAKACS; BUS, 2016, p. 11, tradução nossa). Em consonância com esses resultados, busca-se aplicar os efeitos de animação nos murais de Costa Pinheiro em estrita relação com os eventos previstos nas histórias.

Considerando que o livro ilustrado digital infantil expande a multimodalidade própria do impresso, tirando partido da essência navegativa, interativa, hipertextual, disruptiva do ambiente digital e da hibridação da participação do autor e do leitor/ utilizador (RAMADA PRIETO, 2017), o desenho lúdico-participativo daqui resultante cria uma obra em que a criança constrói a sua própria narrativa. No caso, num intertexto polissémico com a novela de cavalaria, criou-se uma novela de passaria, uma vez que as crianças se deslocam montadas em pássaros de diferentes dimensões e anatomias. Tal como na cavalaria, também o ideal da passaria é praticar o bem, proteger desvalidos e servir a dama amada. A história é construída sob o signo da magia, não só para corresponder às expectativas do género medieval, do imaginário infantil, mas também porque a magia torna coerente os aspectos disruptivos que o livro ilustrado contempla. Assim, entre as personagens, que seguem 
o esquema do romance de cavalaria, encontram-se protagonistas com alguns nomes a ecoarem os da novela Amadís de Gaula (com uma provável versão primitiva de finais do século XIII, princípios do século XIV), Dom Dó e Dama Si (anagrama de Amadís), a amiga Dama Mi, a Dama do Lago (fada da Demanda do Santo Graal, versão original francesa do século XIII), o Mago Laus (última sílaba do nome do feiticeiro Arcalaus, perseguidor de Amadís) e seus cavaleiros negros. Para individualizar estas personagens, acrescentam-se às figuras dos murais, elemento base para a sua identificação, emblemas simbólicos, tais como a espada para o cavaleiro Dom Dó, um toucado nas donzelas, sublinhando-se a beleza de Dama Si, chapéus de fada e de mago para as figuras maravilhosas e espadas para os cavaleiros negros. Apesar de a história ter sido pensada a partir da paleta de cores original, o antagonismo dos universos maravilhosos exige que se introduzam modificações cromáticas em função da expressividade das personagens e do ambiente em que se movem.

Na construção do argumento, desenhou-se uma história tradicional, decalcada da novela de cavalaria, com um cavaleiro amador, donzelas em perigo, cavaleiros e magos hostis e uma fada protetora. No entanto, em simultâneo, criou-se a hipótese de trocar cores, géneros e funções de algumas personagens e, assim, parodiar o esquema convencional. Deste modo, poderá ser a Dama Si a salvar Dom Dó e a Dama do Lago, o Mago Laus e os cavaleiros negros mudam de género e trocam os mundos do bem e do mal que tradicionalmente habitam. Esta metamorfose pode provocar estranhamento, mas, do ponto de vista pedagógico, expõe as crianças a quadros mentais diferentes, o que, em termos de recepção estética e de formação do leitor, constitui uma aprendizagem e uma experiência substantivas.

O trabalho de ilustração consiste na decomposição dos elementos visuais dos murais de Costa Pinheiro, a fim de gerar novas composições a partir dos seus padrões de cores e texturas e, principalmente, dos elementos que irão ganhar movimento no processo de animação digital. Cada elemento - personagem, animal, veículo etc. - para o qual haja uma indicação no roteiro do projeto sobre uma ação (movimento), ou interação do leitor, será extraído da composição do mural por meio de um assistente de edição de imagens a trabalhar a partir de uma fotografia em alta resolução do mural real. As novas composições produzidas irão narrar, a partir da tradição das narrativas não verbais, os acontecimentos do romance de passaria. Uma imagem que conta uma história faz isso a partir de um repertório bastante diferente da tradição verbal, com escolhas compositivas 
e formais para expressar eventos na passagem do tempo e mudança do espaço, o que vai possibilitar o encadeamento da história.

Como se disse antes, a navegação na história oferece duas opções que determinam, respetivamente, a leitura de uma história tradicional, a sua rutura ou a conjugação aleatória das duas, gerando um número elevado de possibilidades. $\mathrm{O}$ avanço da história segue a sinalética da navegação, que marca a sucessão das ações e oferece uma configuração semelhante às imagens dos murais, explorando, sobretudo, desenhos mais pequenos, como sejam as mãos, os pés, as rodas e as hélices.

A animação das personagens sublinha momentos-chave da narrativa, como ocorre, por exemplo, pensando na versão tradicional, na perseguição dos cavaleiros, no rapto da Dama Si, na sua libertação ou nas intervenções maravilhosas, sendo acompanhada por movimentos e sons em sintonia ou parodiando a situação.

Em cada segmento da história recorre-se à hibridação sonora para assinalar momentos de tensão ou de tranquilidade, em modo remix. A expressar a violência dos cavaleiros, combinam-se sons de cavalgadas reais com a abertura de Guilherme Tell, de Rossini; a tematizar o sono mágico que reteve as Damas no Lago Azul, um outro remix, desta feita de canções de embalar (Carla Baptista Alves, World Music for Babies). Na intervenção de cada uma das três personagens com nome de notas musicais, acrescentam-se o piano, a flauta, o violino e o violoncelo que tocarão em simultâneo a nota respetiva.

A segunda história tem como objetivo cultivar o património e a memória das lengalengas e de versos infantis, ao mesmo tempo que, através da geração textual, se criam novos textos, mais ou menos próximos do original, dependendo da quantidade de variantes introduzidas no editor de poesia combinatória, o "Poemário", concebido por Rui Torres e programado por Nuno F. Ferreira, que é uma $l i b^{19} \mathrm{em}$ JavaScript que permite programar textos (poemas, narrativas, cartas etc.) seguindo procedimentos combinatórios.

Assim, considerando que se trata de uma obra para crianças com mais de 6 anos, e tomando como exemplo a cantiga "Todos os patinhos sabem bem nadar / cabeça para baixo, rabinho para o ar", num primeiro nível, a única variante definida são "os patinhos", justamente para manter uma verosimilhança semântica e para evitar demasiada entropia junto das crianças mais novas que assim são iniciadas na poesia

19. Uma lib JavaScript é uma biblioteca (coleção de subprogramas) escrita em JavaScript, permitindo o desenvolvimento de aplicações em JavaScript que podem ser usadas em tecnologias web. 
combinatória e na experiência de coerência semântica e da sua subversão. Porém, com aquele mesmo texto, podem introduzir-se, para outras idades ou para crianças já familiarizadas com o jogo combinatório, mais variantes (por exemplo: nadar, cabeça, rabinho) e listas de variações mais extensas, no caso, mantendo a rima, embora nada obste a que, numa idade mais avançada, se altere essa possibilidade.

Como a imagem se mantém fiel aos murais, cada pássaro e cada criança de cada mural interpretará a sua lengalenga a partir do bico e da boca dos pássaros e das crianças, respetivamente. Serão estes os botões de navegação desta segunda série. Assim, o primeiro mural, dedicado ao nível iniciante, terá cinco textos diferentes, simuladamente ditos por pássaros, e oito, pelos meninos. O ritmo de geração do texto está programado para acompanhar a literacia dos alunos, o que se revela importante para não frustrar a leitura de alunos que estão numa fase inicial de leitura. A acompanhar esta escrita combinatória, as imagens deslocam-se no ecrã, em função da ação referida nos versos, seguindo o ritmo de visualização do texto; o som, sempre em remix, mistura vozes de crianças no recreio, com excertos, por exemplo, d'“A sagração da Primavera”, de Ígor Stravinsky, no caso de serem os meninos os emissores, e de chilreios de pássaros com fragmentos das "Gymnopédies”, de Erik Satie, tratando-se dos pássaros.

A navegação é aleatória, porém, mesmo controlando a extensão dos textos gerados, só poderão ser acionados dois emissores de cada vez. O layout dos novos textos é uniforme, com a exceção da paleta cromática das letras e do fundo, podendo optar-se pela harmonia ou pelo contraste com o fundo onde o texto surge. Nos dois restantes murais, este jogo repete-se com níveis superiores de combinatória, mas a relação multimodal é comum ao primeiro nível.

Do ponto de vista lúdico e estético, espera-se que a criança desenvolva a sensibilidade auditiva e leitora e que, tanto a rima, quando exista, como a combinatória textual, a estimulem a ensaiar, no caderno ou no computador, novas variações. Num mundo ideal, o professor dominaria o editor "Poemário" e auxiliaria o aluno a ensaiar novos textos. Uma tal experiência visual, auditiva e táctil não só educa a literacia digital dos alunos como constitui um importante fator de educação literária, ao revelar como os textos se reescrevem uns aos outros, num mosaico de citações.

A terceira história, "O relógio de Santa Bifana”, é um conto hipertextual pensado para crianças com 9 a 11 anos. Explorando as imagens surrealizantes dos murais, o conto desenvolve-se sob a égide do sonho. Trata-se de uma narrativa não linear na qual, dentro de cada bloco narrativo, as descrições das crianças que habitam a vila são exploradas aleatoriamente, mas o leitor/utilizador só poderá passar para a sequência 
narrativa seguinte quando revelar (através de texto, imagem e/ou som), mediante navegação, todas as crianças do capítulo, as quais, progressivamente, vão povoando a tela. Esta estrutura enumerativa mantém-se em toda a obra, inclusive no final, pelo que, na ótica do destinatário e nas restantes sequências, se acrescentará uma busca labiríntica das personagens apresentadas no princípio do conto e dos respetivos devires.

Tal como na primeira, o trabalho de ilustração da terceira história consiste na recomposição dos elementos visuais dos murais de Costa Pinheiro, gerando peças visuais animadas às quais acrescentar-se-ão elementos sonoros e possibilidades de interação, tanto para a ativação de motion graphics quanto para navegação em uma estrutura multilinear.

Intencionalmente, projeta-se o quotidiano de uma vila surpreendida por um acaso insólito que suspende o tempo cronológico, prolongando o espaço onírico das personagens e também dos animais. Explorando a ludicidade da história, tal como na Novela de passaria, o processo de caracterização das personagens recorre a emblemas que surgem agora espalhados pela tela, para que o leitor os possa atribuir à personagem a que pertencem. Para além do género, não há uma identidade pré-definida. Numa hibridação de papéis entre os autores e a criança leitora, esta ganha autoridade sobre o desenho das personagens e é ela quem atribui o nome à figura que entrou em cena. De algum modo, as crianças são co-criadoras dos habitantes da vila, familiarizando-se com eles e com os seus perfis. Estão, pois, reunidas as condições para que, numa atividade de pós-leitura, os alunos venham a compor, por exemplo, um retrato verbal da sua personagem preferida.

A sonificação será igualmente em remix e a cada objeto, animal ou personagem, corresponde um som motivado. Assim, a obra começa com um trecho de música tibetana combinada com sons de uma vila, a que se associam posteriormente $o$ ondular das asas dos cavalos e o seu trote, prolongando, também a nível do som, a aliança fantasia/realidade que domina o conto.

Embora a aleatoriedade que existe em cada uma das quatro sequências narrativas não ocorra na ordem entre cada uma delas, no desfecho, o leitor pode escolher um dos cinco finais, com diferente complexidade e instaurando um deles num movimento recursivo.

As notas que aqui se deixam sobre o projeto e a sua execução, bem como sobre a sua exploração pedagógica, não têm, naturalmente, caráter exaustivo, visando, antes, exemplificar, do ponto de vista prático, a aplicação dos recursos digitais a duas 
narrativas e a um conjunto de poemas do cancioneiro oral infantil que se pensaram a partir da pintura e se reescreveram em função do ambiente digital.

Embora inicialmente as três obras estejam destinadas a ser projetadas no ecrã do computador, numa fase posterior terão necessariamente de migrar para apps em dispositivos digitais, como o tablet ou o smartphone, ambientes mais adequados às atuais gerações de leitores.

O processo de idealização deste conto hipertextual, enquanto criação de um artefacto digital, poderá beneficiar de suporte conceptual através de instrumentos e conceitos utilizados no contexto de criação de videojogos. No processo de criação desta terceira história, recorre-se por isso a um modelo de concepção da experiência de jogo centrado na participação dos jogadores (PEREIRA; ROQUE, 2013), uma abordagem que tem vindo a ser utilizada na criação de artefactos digitais literários, explorando a interseção de conceitos da área de estudos de jogos digitais e literatura digital (PEREIRA et al., 2018).

Esta abordagem conceptual tem como objectivo ajudar a racionalizar a natureza da participação dos jogadores no contexto de um videojogo. No sentido de auxiliar esse processo de racionalização, são propostas seis perspectivas de participação: brincadeira, sugerindo pensar um videojogo enquanto contexto de participação livre, informal, não estruturado; desafio, para um videojogo enquanto contexto de participação estruturada, de desafio formal ou em função de um objectivo proposto; criação de sentido, sugerindo um videojogo enquanto contexto de participação significante, de criação de sentido; corporealidade, para um videojogo enquanto contexto de participação física, tanto virtual como real; estimulação sensorial, sugerindo pensar um videojogo enquanto espaço de participação multi-sensorial; e, por fim, sociabilidade, isto é, videojogo como espaço de participação social, de estabelecimento de relações entre jogadores.

No processo concreto de idealização desta terceira história, criam-se formas de participação que tiram partido da manipulação digital dos elementos que servem de base material a esta experiência, tanto ao nível do texto verbal como da composição visual, com o objetivo de facilitar a experimentação e criatividade no contexto da literatura eletrónica infantil. Face ao teor surrealizante e figurativo dos elementos visuais de António Costa Pinheiro que servem de base a esta experiência, as perspectivas de participação serão a criação de sentido e de sensorialidade, através da possibilidade de recombinação de elementos visuais e textuais permitindo novos espaços semânticos e estéticos. 
Consideramos também que esta abordagem conceptual, centrada na participação dos jogadores/leitores, poderá ser útil numa fase posterior do projeto, na preparação e avaliação das atividades pedagógicas realizadas com estes novos objetos digitais. Deste modo, estabelecer-se-ão relações entre diferentes estratégias pedagógicas e as características que configuram estes novos objectos de literatura digital infantil, possibilitando diferentes formas de participação.

\section{CONSIDERAÇões Finais}

Entre as possibilidades da escrileitura que caracterizam a literatura eletrónica encontra-se a interação interdisciplinar, nomeadamente entre as artes da escrita e da programação informática, a estrutura não sequencial da informação e a hipertextualidade. $O$ produto artístico criado com estas sinergias exige, por isso, uma nova pedagogia, determinada, entre outros fatores, pela ergodicidade e pela transferência de responsabilidades do(s) autor(es) para os seus receptores. A expressividade das diferenças entre a literatura impressa e o texto literário digital é tal que a escola precisa de se repensar no sentido de uma pedagogia crítica interativa. A iniciação dos alunos na leitura e na utilização da literatura eletrónica, a educação literária e a sua literacia crítica, a exploração de novas modalidades cognitivas, o estímulo à fruição estética, o favorecimento das potencialidades criativas dos alunos no meio digital, como a escrileitura multimediática ou a interação entre a escrita e a sua codificação, são algumas das dimensões que a escola precisa integrar.

Pensando no paradigma das culturas participativas, nas competências dos alunos e no relativo vazio da literatura digital infantil em Portugal, criou-se uma equipa multidisciplinar no sentido de, partindo de um mesmo input, os murais de Costa Pinheiro, criar três níveis de histórias para diferentes faixas etárias $(4,6$ a 8 e 9 a 11 anos) e, dentro de cada uma, uma gradação de complexidade a ser explorada em função da proficiência leitora dos alunos e das suas competências cognitivas.

É certo que algumas das dimensões formais da literatura infantil digital, como o hipertexto ou a multimodalidade, não constituem uma absoluta novidade, pese embora a diferença de meio. Trata-se no entanto de tirar partido de um processo de construção e de ligação que já é familiar às crianças, assim criando artefactos que propiciem o edutainment. Paralelamente, exploram-se em "Murais e Literatura" as virtualidades de uma dupla codificação (ilustração e animação) e dos videojogos, proporcionando aos leitores/utilizadores uma participação multissensorial. 
A remediação dos murais pintados por Costa Pinheiro em 1958 prolonga o programa estético original procurando enriquecer o seu potencial representativo mediante a hibridação de linguagens e dos meios próprios da literatura eletrónica, acrescentando marcas de ludicidade e gamificação, embora prevalecendo a tónica narrativa, ainda que não-linear. No primeiro nível, reescreve-se e parodia-se a novela de cavalaria, num universo ficcional onde a identidade dos cavaleiros se transmuda em pássaros cujo som também reinventa o ambiente do género, que agora se transforma em novela de passaria, com as consequentes metamorfoses (in)esperadas. Também a segunda história tem uma dimensão patrimonial, mantendo uma forte relação com o intertexto, no caso, na poesia tradicional oral infantil. Toda a poesia combinatória, de maior ou menor complexidade, joga com associações motivadas e/ou sonoras por forma a provocar a imersão nessa rica herança cultural e a estimular a sensibilidade poética dos alunos. A terceira história apresenta uma composição mais tradicional, tratando-se de uma narrativa hipertextual que foi objeto de várias alterações ao texto verbal original, justamente porque a escrileitura eletrónica não se compadece com a mecânica da escrita tradicional.

Nos três casos, optou-se quer pelo registo emblemático quer pelas variações sobre modelos tradicionais, de modo a que as crianças sejam levadas a processos de identificação e de estranhamento destas ficções eletrónicas. Estas ruturas face à tradição e ao impresso visam identificar universos conhecidos, mas também criar disponibilidades para o insólito ou inesperado, num espaço que, justamente por ser escolar, pode acompanhar a leitura crítica dessa articulação entre os dois mundos, ao mesmo tempo que incentiva a exploração de outras possibilidades criativas, numa relação de ensino-aprendizagem consentânea com o aluno do século XXI.

\section{REFERÊNCIAS}

AARSETH, E. Cibertexto. Por uma literatura ergódica. Tradução José Augusto Mourão e Maria Leonor Telles. Lisboa, Pedra de Roseta, 2005.

BARBOSA, P. A Ciberliteratura: criação literária e computador. Lisboa: Cosmos, 1996.

BARBOSA, P. Aspectos quânticos do Cibertexto. Cibertextualidades, Porto, n. 1, p. 11-42, 2006.

Disponível em: <https://bdigital.ufp.pt/handle/10284/863>. Acesso em: 31 jan. 2019.

BARRETO, F. Uma Obra Social: Realizada em Coimbra. I. Coimbra: Coimbra Editora, 1970. BOLTER, J.; GRUSIN, R. Remediation: Understanding New Media. Cambridge: The MIT Press, 1999. BOLTER, J. D. Writing Space: Computers, Hypertext and the Remediation of Print. Mahwah, New Jersey: ErlBaum Associates Publishers, 2001. 
Literatura eletrónica para crianças: o caso do projeto "Murais e Literatura...

BOLTER, J. D.; GROMALA, D. Windows and Mirrors: Interaction Design, Digital Art, and the Myth of Transparency. Cambridge, Massachusetts: The MIT Press, 2003.

CASSANY, D. Tras las Líneas. Sobre la Lectura Contemporánea. Barcelona: Editorial Anagrama, 2006.

CASSANY, D. En_Línia. Llegir i Escriure a la Xarxa. Barcelona: GRAÓ, 2011.

CERVERA, J. Teoria de la literatura infantil. 2. ed. Bilbao: Mensajero, 1992.

COBO, C.; MORAVEC, J. Aprendizaje Invisible. Hacia una Nueva Ecología de la Educación.

Barcelona: Publicacions i Edicions de la Universitat de Barcelona, 2011.

CORNIS-POPE, M.; WOODLIEF, A. The rereading/rewriting process: Theory and collaborative, on-line pedagogy. In: HELMERS, M. (Org.). Intertexts: Reading Pedagogy in College Writing Classrooms. Lawrence Erlbaum, 2002. p.146-164.

CUNHA, M. A. A. Literatura infantil: teoria e prática. São Paulo: Ática, 1999. 18 edição.

DELEUZE, G.; GUATTARI, F. Mille Plateaux. Capitalisme et schizophrénie. Paris: Éditions de Minuit, 1980.

DIAS, F. A nova-figuração nas artes plásticas em Portugal: 1958-1975. I. Lisboa: Universidade de Lisboa - Faculdade de Belas-Artes, 2008.

ESKELINEN, M. Six Problems in Search of a Solution: The challenge of cybertext theory and ludology to literary theory. Dichtung Digital, n. 33, 2004. Disponível em: <http://www.dichtungdigital.org/2004/3/Eskelinen/index.htm>. Acesso em: 31 jan. 2019.

EVEN-ZOHAR, I. Polysystem Theory. Poetics Today, v. 11, n. 1, p. 9-26, 1990.

FITTIPALDI, C. O que é uma imagem narrativa. In: OLIVEIRA, I. de (Org). O que é qualidade em ilustração no livro infantil e juvenil. São Paulo: Editora DCL, 2008. p. 93-121.

FUNKHOUSER, C. Prehistoric Digital Poetry: An Archaeology of Forms, 1959-1995. Tuscaloosa, Alabama: University of Alabama Press, 2007.

GLAZIER, L. P. Digital Poetics: The Making Of E-Poetries. Tuscaloosa, Alabama: University of Alabama Press, 2002.

GÓES, L. P. Introdução à literatura para crianças e jovens. São Paulo: Paulinas, 2010.

GRETEL. Actas del Simposio Internacional La literatura en pantalla: textos, lectores y prácticas docentes. Bellaterra: Universidade Autónoma de Barcelona, 2014. Disponível em linha: <http://www. gretel.cat/wp-content/uploads/2016/o5/2014_Actas-del-Simposio-internacional-La-literaturaen-pantalla-textos-lectores-y-prácticas-docentes.pdf >. Acesso em: 18 fev. 2019.

GUSDORF, G. Conhecimento interdisciplinar. In: POMBO, O.; GUIMARÃES, H.; LEVY, T. (Org.). Interdisciplinaridade. Antologia. Porto: Campo das Letras, 2006 [1986]. p. 37-58.

GUSDORF, G. O gato que anda sozinho. In: POMBO, O.; GUIMARÃES, H.; LEVY, T. (Org.). Interdisciplinaridade. Antologia. Porto: Campo das Letras, 2006 [1991]. p. 13-36.

HARGADON, A.; DOUGLAS, J. Y. The pleausures of Immersion and Interaction: Schemas, Scropts, and the Fifth Business. In: HARRIGAN, P.; WARDRIP-FRUIN, N. (Org.). First Person: New Media as story, performance and game. Cambridge, Massachusetts: The MIT Press, 2004. p. 192-206

HAYLES, N. K. Translating Media: Why We Should Rethink Textuality. The Yale Journal of Criticism, V. 16, n. 2, 2003, p. 263-290.

HAYLES, N. K. Electronic Literature: What is it? The Electronic Literature Organization, 2007. Disponível em linha: <http://eliterature.org/pad/elp.html>. Acesso em: 31 jan. 2019. 
HUNT, P. (Org.) Children's Literature. The Development of Criticism. London-New York: Routledge, 1990.

HUNT, P. An Introduction to Children's Literature. New York: Oxford University Press, 1994.

HUNT, P. Crítica, teoria e literatura infantil. São Paulo: Cosac Naify, 2010.

JEGERS, K.; WIBERG, C. Learning While Playing: Design Implications for Edutainment Games. In: WIBERG, M. (Org.). The Interaction Society: Practice, Theories and Supportive Technologies. Hershey: Information Science Publishing, 2005. p. 122-137.

JENKINS, H. et al. Confronting the Challenges of Participatory Culture: Media Education for the 21 st Century. Chicago, Illinois: The John D. and Catherine T. MacArthur Foundation, 2006. Disponível em: <https://www.macfound.org/media/article_pdfs/JENKINS_WHITE_ PAPER.PDF>. Acesso em: 31 jan. 2019.

JIMÉNEZ, S. Y.. Alguns aspectos psicosociales para la reflexón em torno al niño, la literatura, la escuela y la cultura de la imagen. In: CERRILLO, P. C.; PADRINO, J. G. (Coordenadores). El niño, la literatura y la cultura de la imagem. Cuenca: Servico de Publicaciones de la Universidade de Castilla-La Mancha, 1995

LANDOW, G. Teoría del hipertexto. Barcelona: Paidós Ibérica, 1997.

LANDOW, G. Hypertext 3.o. Critical Theory and New Media in an Era of Globalization. Baltimore: The Johns Hopkins University Press, 2009.

LÉVY, P. Tecnologias da inteligência: o futuro do pensamento na era da informática. Tradução de Carlos Irineu da Costa. São Paulo, Ed. 34, 2004.

MACHADO, A. et al. 'Inanimate Alice': The Story of the Series and its Impact in Portugal. MATLIT: Materialities Of Literature, v. 6, n. 3, p. 93-104, 2018. Disponível em linha: <http://impactumjournals.uc.pt/matlit/article/view/5279>. Acesso em: 31 jan. 2019.

MADEJ, K. Towards Digital Narrative for Children: From Education to Entertainment: A Historical Perspective. ACM Computers in Entertainment, n. 1, 2003.

MAGALHÃES, A. M.; ALÇADA, I. Literatura infantil, espelho da alma, espelho do mundo. Revista ICALP, n. 20-21, 1990, p. 111-123.

MANOVICH, L. The Language of New Media. Cambridge, Massachusetts: The MIT Press, 2001.

MANRESA, M; REAL, N. (Org.). Digital Literature for Children - Texts, readers and educational practices. Berna: Peter Lang, 2015.

ME. Perfil dos alunos à saída da escolaridade obrigatória. Lisboa: Ministério da Educação, 2017. Disponível em linha: <https://dge.mec.pt/sites/default/files/Curriculo/Projeto_ Autonomia_e_Flexibilidade/perfil_dos_alunos.pdf $>$. Acesso em: 18 fev. 2019.

ME. Aprendizagens Essenciais: Português — Ensino Básico. Lisboa: Ministério da Educação, 2018. Disponível em linha: <http://www.dge.mec.pt/aprendizagens-essenciais-ensino-basico>. Acesso em: 18 fev. 2019.

ME. Aprendizagens Essenciais: Português - Ensino Secundário. Lisboa: Ministério da Educação, 2018. Disponível em linha: <http://www.dge.mec.pt/aprendizagens-essenciais-ensinosecundario >. Acesso em: 18 fev. 2019.

MINISTÉRIO DA CIÊNCIA, TECNOLOGIA E ENSINO SUPERIOR. Plano estratégico para a área da Ciência Tecnologia e Ensino Superior. Leituras Ciência e Conhecimento. PNL 2027, 2018. 
Literatura eletrónica para crianças: o caso do projeto "Murais e Literatura...

PACKER, R.; JORDAN, K. Multimedia: From Wagner to Virtual Reality. New York and London: W. W. Norton \& Company, 2002.

PEREIRA, L. L.; PORTELA, M.; ROQUE, L. Machines of Disquiet: Textual Experience in the LdoD Archive. MATLIT: Materialities of Literature, v. 6, n. 3, p. 59-71, 2018. Disponível em linha: $<$ http://impactum-journals.uc.pt/matlit/article/view/5200>. Acesso em: 18 fev. 2019.

PEREIRA, L. L.; ROQUE, L. Understanding the Videogame Medium through Perspectives of Participation. DiGRA '13 - Proceedings of the 2013 DiGRA International Conference: DeFragging Game Studies. Volume 7, 2013.

PETERS, M.; LANKSHEAR, C. Critical literacy and digital texts. Educational Theory, v. 46, n. 1, 1996, p. 51-70.

PRENSKY, M. Digital Natives, digital immigrants. On the Horizon, v. 9, n. 5, 2001, p. 1-6. Disponível em linha: <https://doi.org/10.1108/10748120110424816>. Acesso em: 31 jan. 2019.

PULLINGER, K. 'Inanimate Alice' - How We Accidentally Created a Digital Story for Schools. In: MANRESA, M.; REAL, N. (Org.). Digital Literature for Children. Bruxelas: Peter Lang, 2015. p. 213-220.

RAMADA PRIETO, L. Esto No Va de Libros. Literatura Infantil y Juvenil Digital y Educación Literaria. Tese (Doutoramento em Didática da Língua e da Literatura) - Universidade Autónoma de Barcelona, 2017.

RAMOS, A. M. Infância e literatura: contributos para uma leitura da narrativa infantil contemporânea. In: Leitura, literatura infantil e ilustração: Investigação e prática docente. Maia: SerSilito, 2003, p. 117-128

RETTBERG, S. Electronic literature. Cambridge, UK; Medford, MA: Polity Press, 2019.

RODRIGUES, C. Literatura para a infância em Portugal: conceptualização e contextualização histórica. Visão Global, v. 10, p. 161-184, 2007.

RYAN, M.-L. (Org.). Cyberspace Textuality: Computer Technology and Literary Theory. Bloomington: Indiana U P, 1999.

SCHWEBS, T. Affordances of an App. A reading of the Fantastic Flying Books of Morris Lessmore. Nordic Journal of Childlit Aesthetics, n. 5, 2014, p. 1-11.

SHAVIT, Z. Poética da literatura para crianças. Lisboa: Caminho, 2003.

STICHNOTHE, H. Engeneering Stories? A Narratological Approach to Children's Book Apps. Nordic Journal of Childlit Aesthetics, n. 5, 2014, p. 1-9.

TAKACS, Z. K.; BUS, A. G. Benefits of Motion in Animated Storybooks for Children's Visual Attention and Story Comprehension: An Eye-Tracking Study. Frontiers in Psychology, v. 7, article 1591, 2016.

TURRIÓN, C. Narrativa infantil y juvenil digital. ¿Qué ofrecen las nuevas formas al lector literario? Tese (Doutoramento em Didática da Língua e da Literatura) - Universidade Autónoma de Barcelona, 2014.

UNESCO. A Global Framework of Reference on Digital Literacy Skills for Indicator 4.4.2. Montreal: UNESCO-UIS, 2018. Disponível em linha: <http://uis.unesco.org/sites/default/files/documents/ ip51-global-framework-reference-digital-literacy-skills-2018-en.pdf $>$. Acesso em: 18 fev. 2019.

ZILBERMAN, R. A literatura infantil na escola. 11. ed. São Paulo: Global, 2003. 
SOBRe OS AUTORES

Rui Torres é licenciado em Ciências da Comunicação, com Mestrado e Doutoramento em Literatura Luso-Brasileira (Universidade da Carolina do Norte em Chapel Hill, EUA) e Agregação em Ciências da Informação. É professor associado com agregação da Universidade Fernando Pessoa, membro do Board of Directors da Electronic Literature Organization. É poeta digital.

E-mail: rtorres@ufp.edu.pt.

Ana Maria Machado é licenciada em Línguas e Literaturas Modernas (Português-Francês), com Mestrado e Doutoramento em Literatura Portuguesa (Universidade de Coimbra). É professora auxiliar da Universidade de Coimbra e tem experiência na área de Literatura Portuguesa, com pesquisa em literatura medieval, em ensino da literatura e em literatura digital.

E-mail: anamacha@fl.uc.pt.

Ana Albuquerque e Aguilar é graduada em Línguas e Literaturas Clássicas (Universidade de Lisboa), tem Mestrado em Estudos Clássicos - variante Literatura Comparada (Universidade de Lisboa) e é Doutoranda em Materialidades da Literatura (Universidade de Coimbra). É professora do Ensino Secundário e pesquisadora do Centro de Literatura Portuguesa da Universidade de Coimbra. Tem experiência na área de ensino da língua e da literatura e tem concentrado a sua pesquisa em educação literária, literatura digital, literatura infantil e juvenil. É bolseira de doutorado da Fundação para a Ciência e Tecnologia. E-mail: anasalbuquerque@gmail.com.

Júlia Andrade é graduada em Relações Públicas (Pontifícia Universidade Católica de Minas Gerais - Brasil) com mestrado em Literatura de Língua Portuguesa: Investigação e Ensino (Universidade de Coimbra - Portugal) e é atualmente doutoranda em Materialidades da Literatura (Universidade de Coimbra). Tem experiência na área de escrita criativa e formação de leitores, com pesquisa nos seguintes temas: álbum ilustrado, leitura de imagens, livros infantis, design gráfico, formação de leitores. Bolsista CAPES (Coordenação de Aperfeiçoamento de Pessoal de Nível Superior- Brasil) 1858.2015-07.

E-mail: juliazuza@gmail.com. 
Thales Estefani é graduado em Comunicação Social e habilitado em Produção Editorial (Universidade Federal do Rio de Janeiro - Brasil), tem Mestrado em Artes, Cultura e Linguagens (Universidade Federal de Juiz de Fora - Brasil) e é doutorando em Materialidades da Literatura (Universidade de Coimbra). Tem experiência nas áreas de produção editorial e comunicação visual, com pesquisa nos seguintes temas: álbum ilustrado, intermedialidade, literatura digital, interatividade e ciência cognitiva. É bolseiro de doutorado da Fundação para a Ciência e Tecnologia. E-mail: thales.chaun@gmail.com.

Luís Lucas Pereira tem Mestrado em Engenharia Informática (Universidade de Coimbra) e é doutorando do Plano Doutoral em Ciências e Tecnologias da Informação (Universidade de Coimbra). É co-fundador do estúdio de desenvolvimento criativo Maria Adelaide (http://mariaadelaide.com). Tem interesses de investigação nas áreas de Interação Humano-Computador e Literatura Digital. E-mail:1pereira@dei.uc.pt.

Recebido em 23 de novembro de 2018 e aprovado em 17 de dezembro de 2018. 